\title{
Conservation of Tropical Forests
}

$\mathrm{T}$ HREE articles which have appeared in the Empire Forestry Journal (vol. 12, No. 1, 1933) display the difficulties which exist in conserving and putting to their fullest utilisation the tropical forests of the Empire. To take the second case first, Sir Ralph Pearson, formerly director of the Forest Products Laboratory at Princes Risborough, discusses the problem of creating and developing markets for Empire hardwood timbers at home.

Sir Ralph briefly reviews the reasons why wellknown timbers have not found favour amongst markets in Great Britain, ascribing some of the causes to the fact that the consignments sent over were often not carefully chosen; nor, with the facilities available in the forests, was there much chance of their being so chosen when the shorthanded and over-worked forest officer was himself responsible for their dispatch. Sir Ralph deprecates trying to push too many new timbers upon the markets at the same time, and points out the way in which chosen timbers should be forwarded and tested.

A second article, by Mr. J. B. Clements, conservator of forests in Nyasaland, treats of the cultivation of finger millet (Eleusine coracana) and its relation to shifting cultivation in Nyasaland. This article, and the practice dealt with, is typical of one of the chief sources of the disappearance of valuable forests in tropical countries, the difficulties facing the administration, not always convinced of the increasing injury supervening, in weaning the people from so wasteful a form of primitive agriculture; and finally, of the troubles of a forestry department well aware of the evils resulting from the practice.

"It is therefore clear that shifting cultivation in Nyasaland is accelerated to a very considerable extent by the growing of Eleusine coracana under prevalent methods. Compared with the growing of other crops, the requisites of the millet make extravagant demands as regards the use of land, and systematic burning of the top soil combined with flat cultivation when carried out on any large scale leads to widespread loss and impoverishment of the soil, particularly in hilly country. Rapid deforestation inevitably takes place in any wooded country where the millet is grown, as conditions are there ideal for providing both new soil for each crop and fuel for heating the soil.",

The third article, by N. V. Brasnett, conservator of forests, Uganda, discusses the formation of State forests, and forest rights and privileges of local inhabitants in Uganda. After briefly reviewing the position of the colony from the day, in 1890, when Capt. (now Lord) Lugard signed a treaty on behalf of the British East Africa Co. with the King of Buganda, the declaration of the British protectorate in 1894, and Sir Harry Johnston's arrival in 1899 and subsequent organisation of the administration of the country, the author concentrates upon the various arrangements, regulations and ordinances for the management of the forest areas of the country.

It is impossible to deal with the varying policies to which succeeding administrations subjected the forests after the first and promising lines were laid down. But a perusal furnishes evidence that one of the past flaws in colonial administration has been the refusal or inabilitiy of those responsible for the future welfare of their charges to lay down a definite forest policy, based cn wide views, and to adhere to it.

Mr. Brasnett ends his summary of the present position of the forests in Uganda with the sentence : "When formation is completed it is estimated that the State forests of Uganda will constitute just about $2 \%$ of the total land area of the Protectorate, and the total forest area, including private woodlands and the valuable savannah, just over $3 \%$, so that it is obviously essential to preserve the whole of this small percentage." Many conversant with the tropical forest and the importance it plays in countries where it exists would consider the percentage dangerously low.

\section{Band Spectrum of PN and its Significance}

$\mathrm{O}^{\mathrm{n}}$ the diatomic emitters of band spectra, few have been more extensively studied than the 14-electron molecules $\mathrm{N}_{2}$ and $\mathrm{CO}$, which are responsible for many observed band systems and unlike most emitters, are well known as stable molecules rather than as intermediate products in chemical reactions or equilibrium products at high temperatures. Emitters which are chemically or spectroscopically analogous to these two have, as would be expected, also received considerable attention, the best known examples being the 30 -electron molecule $\mathrm{P}_{2}$ and the 22-electron molecules $\mathrm{SiO}$ and CS.

To the latter category the PN molecule becomes an interesting addition as the result of the recent dis. covery and analysis, by J. Curry, L. Herzberg and G. Herzberg ${ }^{1}$, of an ultra-violet band system which is produced by an electrical discharge through a mixture of phosphorus vapour and pure nitrogen. With a heavy discharge (about $6000 \mathrm{v}$. and $\frac{1}{3} \mathrm{amp}$.) in a water-cooled tube, this $\mathrm{PN}$ system has been photographed in the first and second orders of a $3-\mathrm{m}$. grating, and both the vibrational and rotational structures analysed.

The new bands extend from $\lambda 2375$ to $\lambda 2992$, are degraded towards the red and have a fine structure characteristic of the electronic transition designated as ${ }^{1} \Pi \rightarrow{ }^{1} \Sigma$. The system is therefore similar to those of the iso-electronic molecules $\mathrm{CS}$ and $\mathrm{SiO}$ in the same spectral region and to the well-known fourth position system of $\mathrm{CO}$ and the Lyman system of $\mathrm{N}_{2} \cdot{ }^{2}$ The $\mathrm{P}_{2}$ ultra-violet system is not analogous to these as it is due to a ${ }^{1} \Sigma \rightarrow{ }^{1} \Sigma$ transition ${ }^{3}$; other and less refrangible $\mathrm{P}_{2}$ bands are known, some of which may, when analysed, prove to belong to the expected ${ }^{1} \Pi \rightarrow 1 \Sigma$ system.

From the accompanying table of the more important numerical constants for the electronic states concerned, it is clear that the three 22-electron molecules are similar to one another and intermediate to the 14-electron and the 30-electron molecules in respect of the vibrational coefficients $\omega_{e}$ and $x_{e} \omega_{e}$, the rotational coefficient $B_{0}$ and the equilibrium inter- 